\title{
Clinical assessment and ultrasonography in the follow-up of enthesitis in patients with spondyloarthritis: a multicenter ultrasound study in daily clinical practice
}

This article was published in the following Dove Press journal:

Open Access Rheumatology: Research and Reviews

\author{
Wolfgang Hartung' \\ Axel Nigg ${ }^{2}$ \\ Johannes Strunk ${ }^{3}$ \\ Björn Wolff ${ }^{4}$
}

'Department of Rheumatology/ Clinical Immunology, Asklepios Medical Center, 93077 Bad Abbach, Germany; ${ }^{2}$ Medizinische Klinik II Kreisklinik Altötting-Burghausen, 84489 Burghausen, Germany;

${ }^{3}$ Hospital Porz am Rhein, 51149 Köln, Germany; ${ }^{4} \mathrm{AbbVie}, 65189$ Wiesbaden, Germany
Correspondence: Wolfgang Hartung Department of Rheumatology/Clinical Immunology, Asklepios Medical Center, Kaiser-Karl-V-Allee 3, 93077 Bad Abbach, Germany

Email w.hartung@asklepios.com
Objectives: The aim of this study was to compare the clinical Maastricht Ankylosing Spondylitis Enthesitis Score (MASES) and an established ultrasound enthesitis score following treatment change in patients with spondyloarthritis and enthesitis with respect to the sensitivity to change and health-related quality of life.

Materials and methods: About 145 patients with active ankylosing spondylitis $(n=65)$, psoriatic arthritis without $(n=66)$ or with $(n=14)$ axial involvement undergoing intensification of their treatment were included in this multicenter study. At baseline, after 3 and 6 months, 13 entheses were scored by MASES, ultrasonography was performed for 14 entheses. Assessments of clinical, laboratory and patient-reported outcome measurements were performed.

Results: During 6 months of follow-up, MASES was reduced from 5.57 to $3.12(P<0.001)$, which was similar to the reduction of the power Doppler sum score from 5.47 to $2.88(P<0.001)$. Both MASES and power Doppler ultrasound were responsive at the 3-month follow-up visit, as indicated by a high sensitivity to change in patients initiating anti-tumor necrosis factor treatment ( -0.96 for MASES and -0.74 for power Doppler ultrasound). Improvement of enthesitis did not correlate with patient-reported outcomes.

Conclusion: Clinical assessment by MASES and power Doppler sonography as well reflects anti-tumor necrosis factor treatment response in patients with spondyloarthritis. Improvement of enthesitis did not correlate with changes in quality of life measures.

Keywords: sonography, spondyloarthritis, enthesitis, psoriatic arthritis, power Doppler

\section{Introduction}

Enthesitis is a common manifestation of axial spondyloarthritis ( $\operatorname{axSpA}$ ) and psoriatic arthritis (PsA), occurring in up to $40 \%$ of patients with SpA. Because of the pathognomonic relevance, enthesitis is a major criterion in many classification systems for axSpA and PsA. Enthesitis is also one of the three entry criteria for the Assessment of Spondyloarthritis International Society (ASAS) classification criteria for peripheral SpA. ${ }^{1}$ Several scores have been published to reflect the inflammatory activity and treatment response of enthesitis in SpA. ${ }^{2}$ The Maastricht Ankylosing Spondylitis Enthesitis Score (MASES) includes 13 entheses and was introduced as a feasible instrument for therapeutic follow-up. It has been shown that clinical evaluation underestimates enthesitis involvement compared with imaging modalities, such as magnetic resonance imaging and ultrasound (US). US imaging is able to identify soft tissue and bony changes, and may also be used to assess the degree of inflammation with power or color Doppler. 
Recently, a consensus-based US definition of enthesitis was published by the outcome measure in rheumatology clinical trails (OMERACT) group, ${ }^{3}$ thus confirming the impact of sonography in the evaluation of enthesitis.

The aim of this study was to compare the MASES, an established clinical enthesitis index, with a well-accepted US score, ${ }^{4}$ with respect to sensitivity to change, thus reflecting treatment response and correlation with health-related quality of life.

\section{Materials and methods}

The aim of this study was to compare the clinical MASES and an established US enthesitis score following treatment change in patients with $\mathrm{SpA}$ and enthesitis with respect to the sensitivity to change and health-related quality of life.

One hundred forty-five SpA patients (68 females and 77 males) who fulfilled the modified New York criteria for ankylosing spondylitis (AS) or the classification of PsA criteria for PsA were enrolled by 40 sites in the study. The study protocol was reviewed and approved by the local ethics committee of the University of Regensburg, and the study was conducted in accordance with the Declaration of Helsinki. All persons gave their written informed consent prior to their inclusion in the study. Inclusion criteria were active disease (Bath Ankylosing Spondylitis Disease Activity [BASDAI]) $\geq 4$ for patients with AS and Disease Activity Score- 28 joints (DAS28) $\geq 3.2$ for patients with PsA, patient reported pain at the Achilles tendon or at least at three other entheseal sites, as well as need for a treatment change at baseline according to the treating rheumatologist. Treatment change was defined as starting conventional synthetic (cs) or biologic (b) diseasemodifying anti-rheumatic drug (DMARD) therapy either as mono or combination therapy or switching medication between cs and bDMARDs

\section{Clinical and laboratory assessment}

At baseline, after 3 and 6 months, patients had 13 entheseal sites dichotomous scoring for tenderness according to the MASES, namely bilateral first costochondral joint, seventh costochondral joint, posterior superior iliac spine, anterior superior iliac spine, iliac crest, proximal insertion of the Achilles tendon, and the fifth lumbar spinosus process. In addition, BASDAI, Bath Ankylosing Spondylitis Metrology Index (BASMI), and Bath Ankylosing Spondylitis Functional Index (BASFI) scores were calculated. Disease activity was calculated according to the DAS28 for PsA patients. All patients completed the EuroQol-5 Dimensions (EQ-5D), the EuroQol-5 Dimensions Visual Analog
Scale, and the Health Assessment Questionnaire (HAQ) at each visit.

\section{US assessment}

As previously described by Naredo et al, ${ }^{4}$ assessment by power Doppler (PD) US (PDUS) imaging included the following bilateral entheses: lateral epicondyle, medial epicondyle, quadriceps tendon, proximal patellar tendon, distal patellar tendon, Achilles tendon and plantar fascia. For each site, the grading was as follows, up to a maximum score of 28:0, no PD signal; 1, intra- or peri-entheseal vascularization and 2, peri- and intra-entheseal detectable PD signal. Each investigator was trained by highly experienced sonographers before conducting the study. PD assessment was performed by selecting a region of interest that included the bony margins, entheseal site and the surrounding soft tissues. Pulse repetition frequency was adjusted to the lowest value with acceptable artifacts and maximum sensitivity. Color gain was set just below the color noise level. The presets were unchanged throughout the follow-up visits.

\section{Statistical assessment}

Statistical analysis was performed with SPSS statistical software (version 17.02; SPSS, Inc., Chicago, IL, USA). For quantitative parameters, such as the number of patients, age of patients and disease activity, the mean \pm SD and range were determined. Significant changes between visits were calculated using the Wilcoxon test. $P<0.05$ was considered statistically significant. Inter- and intra-reader agreement was calculated using kappa coefficients between the readers. The kappa coefficients were divided as follows: $<0.0=$ poor, $0-0.20=$ slight, $0.21-0.40=$ fair, $0.41-0.60=$ moderate, $0.61-0.80=$ substantial, and $0.81-1.0=$ almost perfect agreement. Agreement between readers was also calculated using percentages.

\section{US inter- and intra-reader reliability}

Twenty-five readers took part in the US reliability substudy. The reading of one specialist in musculoskeletal US (WH) was used as the imaging gold standard. Fifty stored images were scored for the presence of intra- and peri-entheseal PD signals using blinded conditions. For intra-reader testing, eight images were evaluated twice.

\section{Results}

Patients with AS $(n=65)$ and patients with PsA $(n=66)$ had moderate disease activity (mean BASDAI, 5.37 \pm 1.57 , and mean DAS28, 4.05 \pm 0.96 , respectively) and long- 
standing entheseal pain at the Achilles tendon. The duration of symptoms of enthesitis ( $7.47 \pm 10.2$ years), as well as the duration of enthesitis after diagnosis (5.26 \pm 8.53 years), were comparable between patients with AS and PsA. The gender distribution was $\sim 1: 1$ in both cohorts, with $44.6 \%$ female patients with AS vs $47 \%$ female patients with PsA.

The mean \pm SD age of SpA patients was 47.5 \pm 11.6 years (range, 18-75 years). Patients with PsA were older (mean age, 50.4 \pm 9.54 years) than the patients with AS (mean age, $42.9 \pm 11.5$ years; $P<0.001)$ and had a higher body mass index (BMI; mean BMI, $29.0 \pm 5.0 \mathrm{~kg} / \mathrm{m}^{2}$ and $26.2 \pm 5.7 \mathrm{~kg} /$ $\mathrm{m}^{2}$, respectively; $P=0.001$ ).

Prior to study enrollment, $36.4 \%, 50.8 \%$ and $25.8 \%$ of all patients with $\mathrm{SpA}, \mathrm{AS}$ and PsA, respectively, were naïve to csDMARDs and $67.1 \%, 64.6 \%$ and $72.3 \%$ of all patients with $\mathrm{SpA}, \mathrm{AS}$ and PsA were naïve to biologic treatment. At the time of enrollment, 18 patients with AS (27.7\%) and 50 patients with PsA (75.8\%) were receiving csDMARD therapy. The use of anti-tumor necrosis factor (TNF) agents was slightly higher in patients with AS ( $n=23$ [35.4\%]) compared with patients with PsA $(n=19[28.8 \%])$. The use of prednisone in patients with $\mathrm{AS}(\mathrm{n}=15[23.1 \%])$ and patients with PsA ( $n=15$ [22.7\%]) was comparable, as was the use of nonsteroidal anti-inflammatory drugs $(n=31$ [47.7\%]; $n=28$ [42.4\%], respectively).

The use of anti-TNF agents as monotherapy increased from $13.8 \%$ at baseline to $32.4 \%$ at the 6-month follow-up visit. The combination of anti-TNF agents with DMARDs increased from $6.2 \%$ at baseline to $11 \%$ at the 6 -month follow-up visit. Twenty-one patients with SpA (14.5\%) began DMARD therapy during the study.

\section{Clinical, laboratory and PDUS parameters}

The clinical, laboratory and PDUS parameters at baseline and at the 3- and 6-month follow-up visits are shown in Table 1. A highly significant improvement in all clinical (BASDAI, DAS28, MASES, PAIN-VAS [0-100], PGA and EQ-VAS), functional (BASMI and BASFI), and health-related quality of life (HAQ and EQ-5D) scores, as well as laboratory parameters (CRP and ESR), was apparent at the 3- and 6-month follow-up visits $(P<0.001)$, see Figures $1-6$. MASES and the sum score of the peri- and intra-entheseal PDUS signals of seven bilateral entheses improved significantly at the 3-and 6-month follow-up visits $(P<0.001)$. Both MASES and PDUS were responsive at the 3-month follow-up visit, as indicated by a high sensitivity to change in patients initiating anti-TNF treatment ( -0.96 for MASES and -0.74 for PDUS).

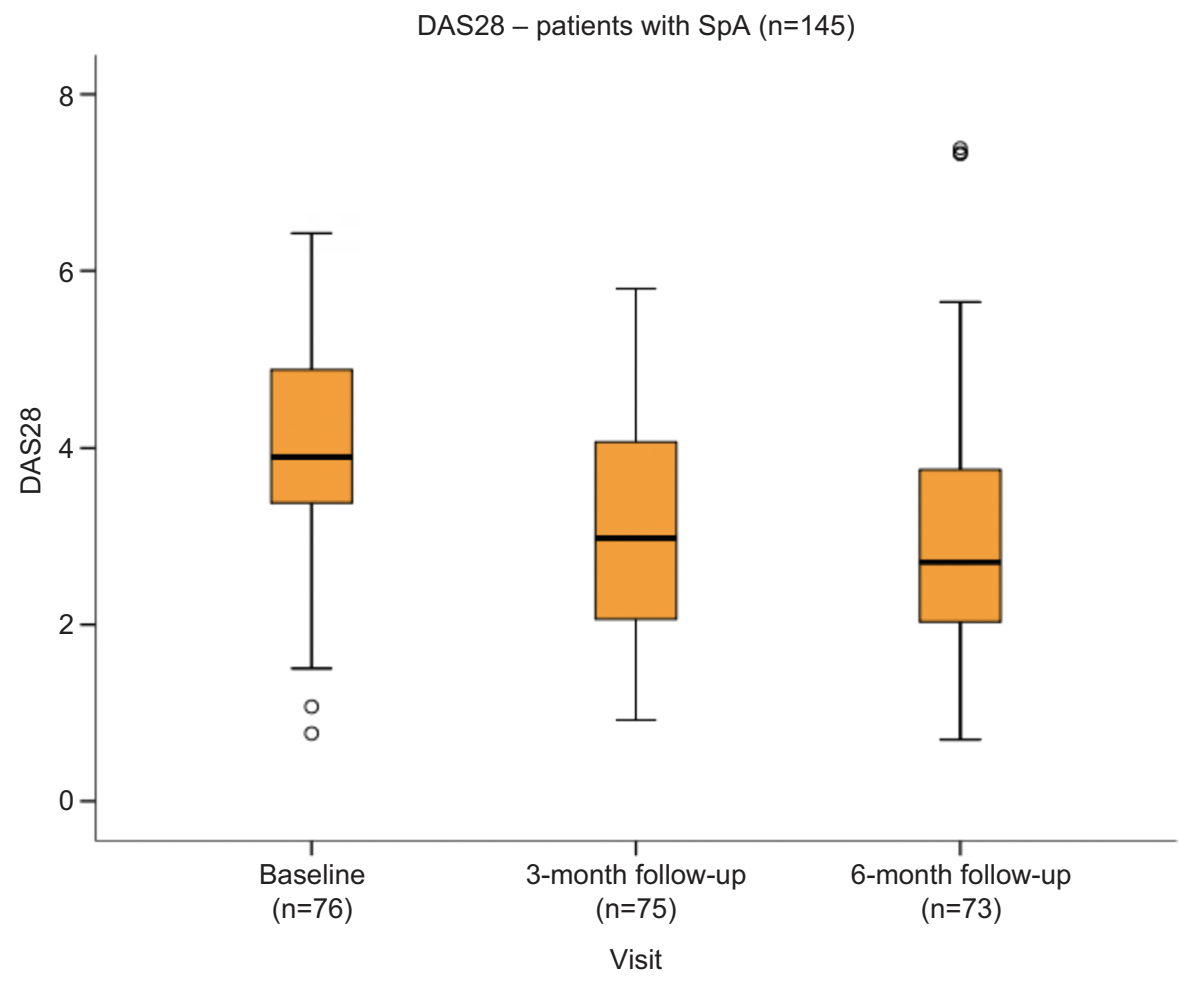

Figure I DAS28 at baseline, and 3 and 6 months of follow-up.

Abbreviations: DAS28, Disease Activity Score-28 joints; SpA, spondyloarthritis. 


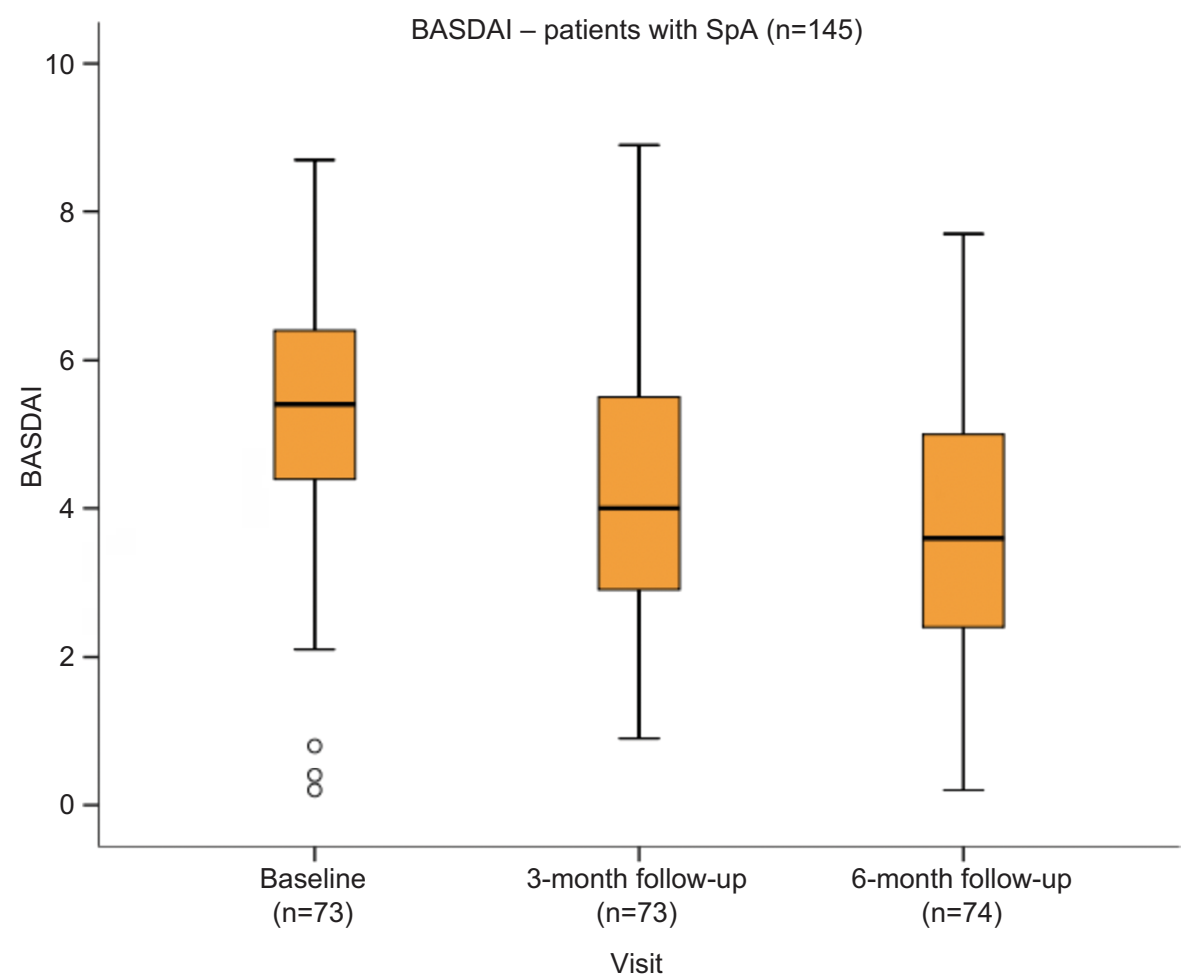

Figure 2 BASDAl at baseline, and 3 and 6 months of follow-up.

Abbreviations: BASDAI, Bath Ankylosing Spondylitis Disease Activity; SpA, spondyloarthritis.

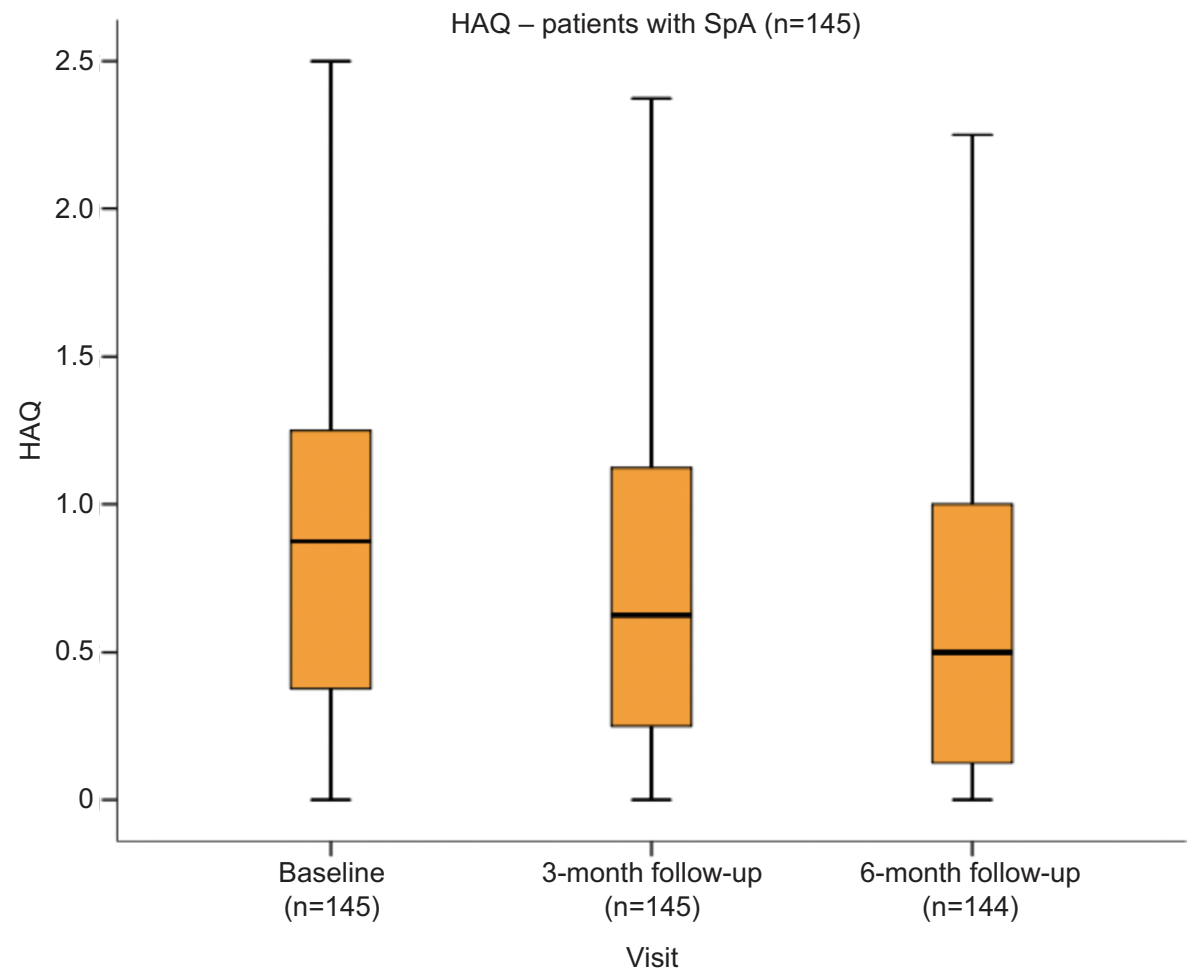

Figure $3 \mathrm{HAQ}$ at baseline, and 3 and 6 months of follow-up.

Abbreviations: HAQ, Health Assessment Questionnaire; SpA, spondyloarthritis. 
$E Q-5 D$ Index - patients with SpA $(n=145)$

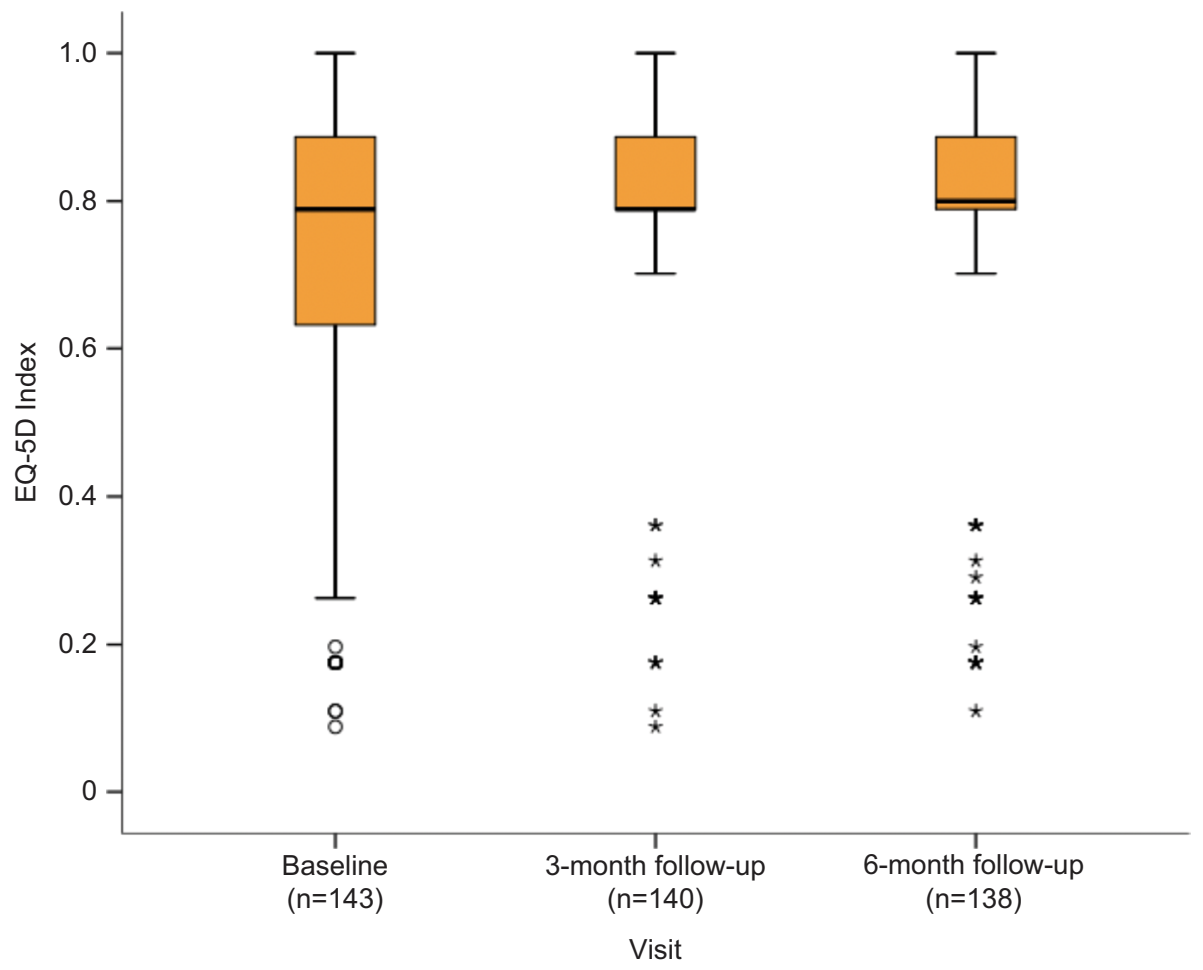

Figure 4 EQ-5D at baseline, and 3 and 6 months of follow-up.

Abbreviations: EQ-5D, EuroQol-5 Dimensions; SPA, spondyloarthritis.

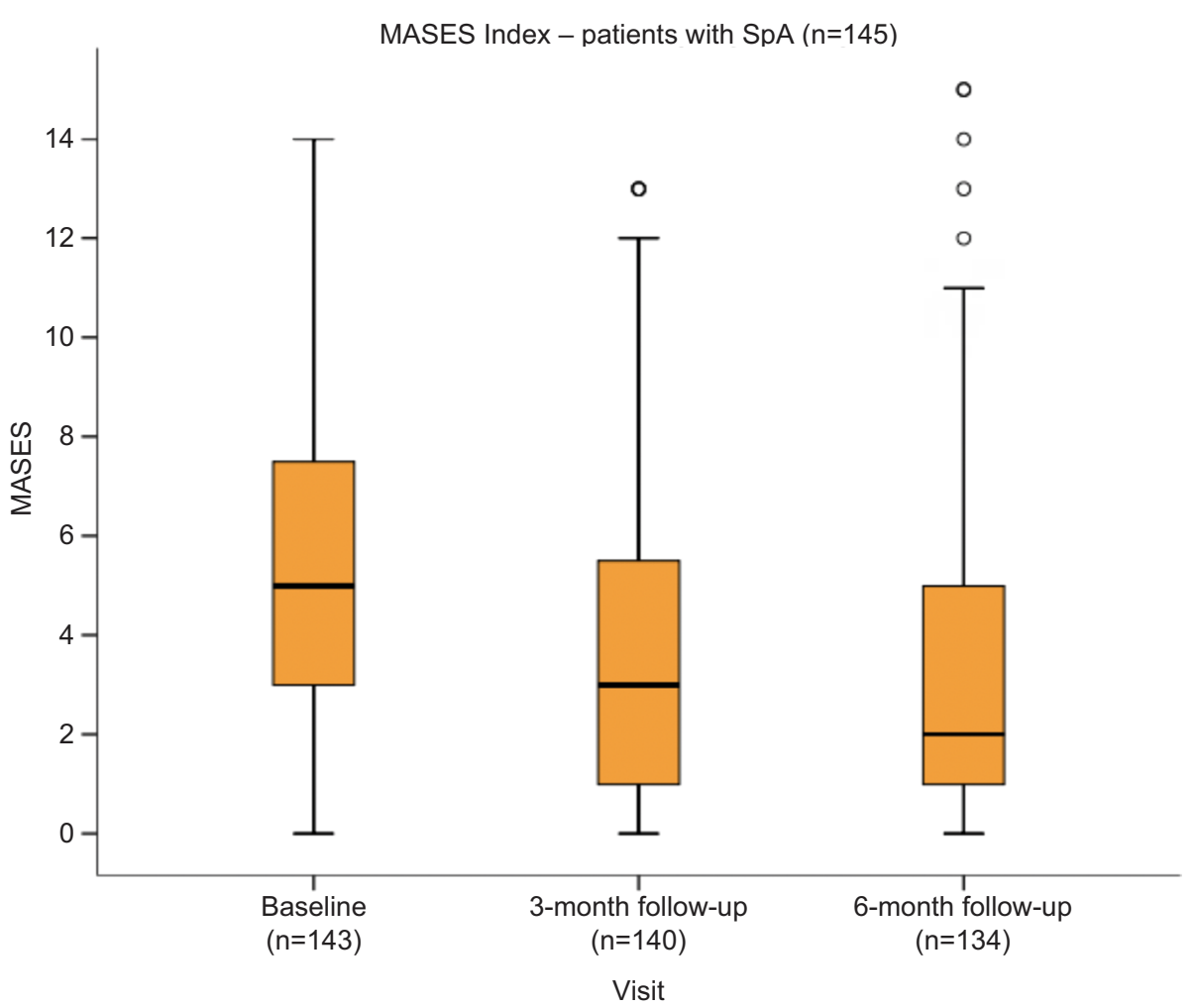

Figure 5 MASES at baseline, and 3 and 6 months of follow-up.

Abbreviations: MASES, Maastricht Ankylosing Spondylitis Enthesitis Score; SpA, spondyloarthritis. 


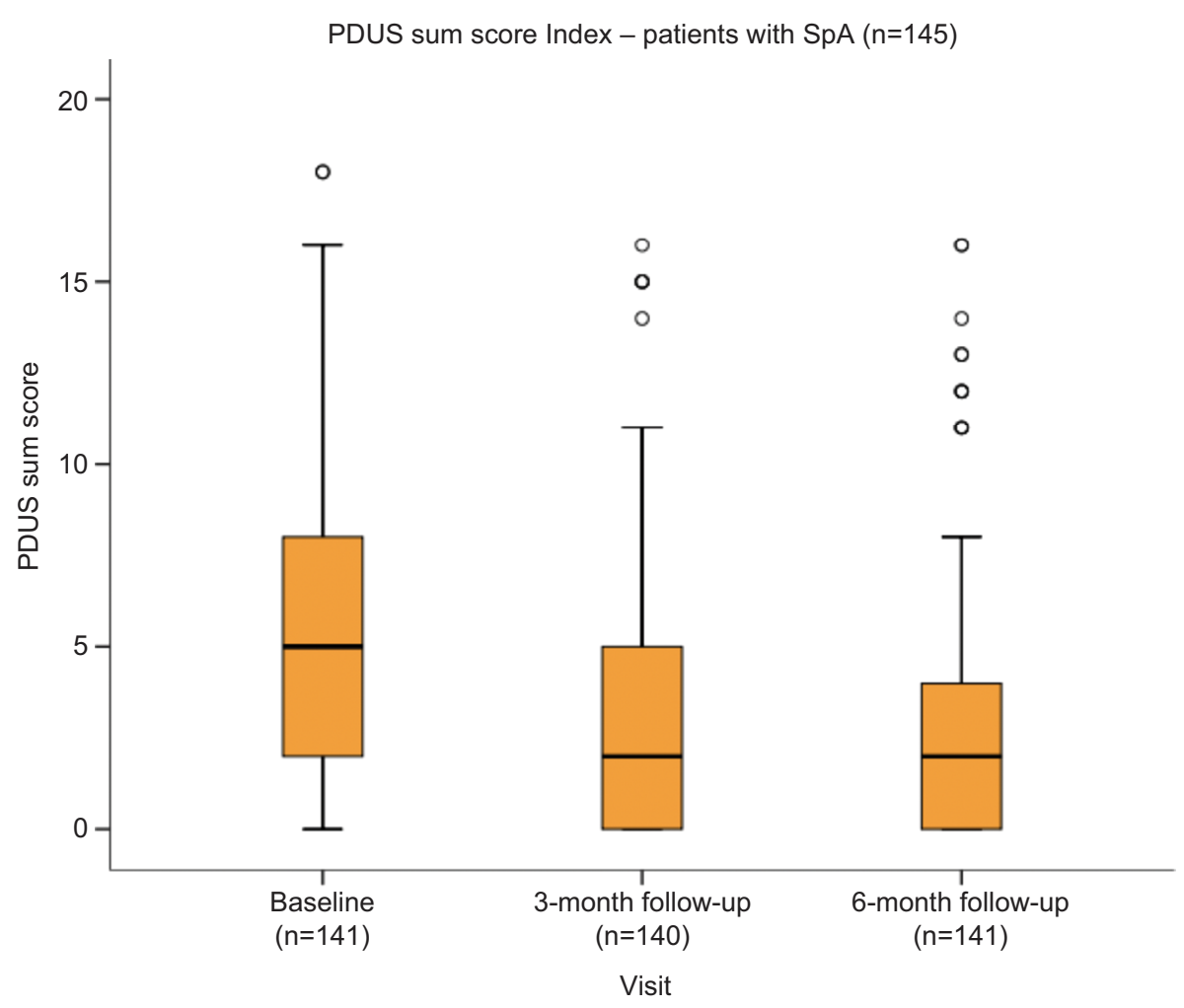

Figure 6 PDUS sum score at baseline, and 3 and 6 months of follow-up.

Abbreviations: PDUS, power Doppler ultrasound; SpA, spondyloarthritis.

Table I Clinical, laboratory and PDUS parameters at baseline, and the 3- and 6-month follow-up visit of patients with SpA (n=I45)

\begin{tabular}{|l|l|l|l|}
\hline Parameter & $\begin{array}{l}\text { Baseline } \\
\text { (SD) }\end{array}$ & $\begin{array}{l}\text { After 3 } \\
\text { months (SD) }\end{array}$ & $\begin{array}{l}\text { After 6 } \\
\text { months (SD) }\end{array}$ \\
\hline DAS28 & $4.00( \pm 1.09)$ & $3.05^{\mathrm{a}}( \pm 1.28)$ & $3.08^{\mathrm{a}}( \pm I .54)$ \\
BASDAI & $5.40( \pm 1.63)$ & $4.17^{\mathrm{a}}( \pm 1.84)$ & $3.66^{\mathrm{a}}( \pm I .74)$ \\
CRP $(\mathrm{mg} / \mathrm{L})$ & $14.10( \pm 29.9)$ & $5.78^{\mathrm{a}}( \pm 11.7)$ & $5.42^{\mathrm{a}}( \pm 10.7)$ \\
ESR $(\mathrm{mm} / \mathrm{h})$ & $19.10( \pm 19.9)$ & $11.90^{\mathrm{a}}( \pm 14.3)$ & $11.30^{\mathrm{a}}( \pm I 1.3)$ \\
VAS $(0-100)$ pain & $59.80( \pm 22.8)$ & $42.70^{\mathrm{a}}( \pm 24.0)$ & $39.80^{\mathrm{a}}( \pm 26.3)$ \\
HAQ & $0.86( \pm 0.57)$ & $0.69^{\mathrm{a}}( \pm 0.57)$ & $0.65^{\mathrm{a}}( \pm 0.57)$ \\
EQ-5D & $0.67( \pm 0.27)$ & $0.78^{\mathrm{a}}( \pm 0.20)$ & $0.78^{\mathrm{a}}( \pm 0.24)$ \\
MASES & $5.57( \pm 3.37)$ & $3.70^{\mathrm{a}}( \pm 3.28)$ & $3.12^{\mathrm{a}}( \pm 3.40)$ \\
PDUS sum score & $5.47( \pm 3.97)$ & $3.39^{\mathrm{a}}( \pm 3.73)$ & $2.88^{\mathrm{a}}( \pm 3.61)$ \\
\hline
\end{tabular}

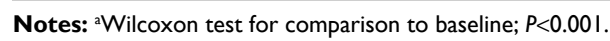

Abbreviations: BASDAI, Bath Ankylosing Spondylitis Disease Activity Index; CRP, C-reactive protein; DAS28, Disease Activity Score-28 joints; EQ-5D, EuroQol-5 Dimensions; ESR, erythrocyte sedimentation rate; HAQ, Health Assessment Questionnaire; MASES, Maastricht Ankylosing Spondylitis Enthesitis Score; PDUS, power Doppler ultrasound; VAS, visual analog scale.

\section{Distribution of PDUS signals}

In patients with AS, the most frequent PDUS signals were (consistent with the inclusion criteria) peri- and intra-entheseal PD signals of the Achilles tendon (39\% and $30 \%$, respectively), followed by peri-entheseal PD signals of the plantar fascia (26\%; Table 2). Among patients with PsA, peri-entheseal PD signals of the Achilles tendon were the most frequently observed (38\%) and peri- and intra-entheseal PD signals at the plantar fascia were the least frequently observed $(2 \%$ and $8 \%$, respec- tively). Completing the PDUS score for all entheses took on average 10 minutes.

\section{Comparison of MASES and PDUS at the Achilles tendon}

MASES and the PDUS score have only the Achilles tendon in common. Of the patients with AS and PsA, 70\% had pain at the proximal insertion of the Achilles tendon as measured by the MASES, whereas only $62 \%$ and $58 \%$ of patients with AS and PsA had a PDUS signal at the Achilles tendon, respectively. 
Table 2 Distribution of power Doppler signal at the entheseal sites at baseline

\begin{tabular}{|c|c|c|c|c|c|}
\hline Entheses & PD signal & $\begin{array}{l}\text { All \% } \\
(n=145)\end{array}$ & $\begin{array}{l}\text { AS \% } \\
(n=65)\end{array}$ & $\begin{array}{l}\text { PsA \% } \\
(n=66)\end{array}$ & $\begin{array}{l}\text { PsA + axial } \\
\%(n=14)\end{array}$ \\
\hline \multirow{6}{*}{$\begin{array}{l}\text { Common extensor } \\
\text { tendon }\end{array}$} & Intraentheseal, left & $21.40(31)$ & $16.9(11)$ & $25.80(17)$ & $21.40(3)$ \\
\hline & Perientheseal, left & 26.90 (39) & $24.60(16)$ & $25.80(17)$ & $42.90(6)$ \\
\hline & Intraentheseal, right & $24.80(36)$ & $21.50(14)$ & $24.20(16)$ & $42.90(6)$ \\
\hline & Perientheseal, right & $27.60(40)$ & $20.00(13)$ & $34.80(23)$ & $28.60(4)$ \\
\hline & PDUS sum score \pm & $1.07 \pm 1.27$ & $0.89 \pm 1.22$ & $1.2 \pm 1.34$ & $1.36 \pm 1.22$ \\
\hline & SD (range 0-4) & $(0-4)$ & $(0-4)$ & $(0-4)$ & $(0-3)$ \\
\hline \multirow[t]{6}{*}{ Common flexor tendon } & Intraentheseal, left & $16.60(24)$ & $12.30(8)$ & $19.70(13)$ & $21.40(3)$ \\
\hline & Perientheseal, left & $14.50(21)$ & $13.80(9)$ & $13.60(9)$ & $21.40(3)$ \\
\hline & Intraentheseal, right & $17.90(26)$ & $13.80(9)$ & $21.20(14)$ & $21.40(3)$ \\
\hline & Perientheseal, right & $17.90(26)$ & $15.40(10)$ & $21.20(14)$ & $14.30(2)$ \\
\hline & PDUS sum score \pm & $0.72 \pm 1.10$ & $0.56 \pm 0.94$ & $0.86 \pm 1.25$ & $0.79 \pm 1.05$ \\
\hline & SD (range 0-4) & $(0-4)$ & $(0-4)$ & $(0-4)$ & $(0-3)$ \\
\hline \multirow[t]{6}{*}{ Quadriceps tendon } & Intraentheseal, left & $15.20(22)$ & $16.90(11)$ & $13.60(9)$ & $14.30(2)$ \\
\hline & Perientheseal, left & $16.60(24)$ & $15.40(10)$ & $12.10(8)$ & $42.90(6)$ \\
\hline & Intraentheseal, right & $21.40(31)$ & $20.00(13)$ & $22.70(15)$ & $21.40(3)$ \\
\hline & Perientheseal, right & $20.70(30)$ & $24.60(16)$ & $15.20(10)$ & $28.60(4)$ \\
\hline & PDUS sum score \pm & $0.74 \pm 1.15$ & $0.75 \pm 1.23$ & $0.66 \pm 1.06$ & $1.07 \pm 1.14$ \\
\hline & SD (range 0-4) & $(0-4)$ & $(0-4)$ & $(0-4)$ & $(0-3)$ \\
\hline \multirow{6}{*}{ Proximal patellar tendon } & Intraentheseal, left & $9.00(13)$ & $15.40(10)$ & $4.50(3)$ & $0(0)$ \\
\hline & Perientheseal, left & $19.30(28)$ & $24.60(16)$ & $18.20(12)$ & $0(0)$ \\
\hline & Intraentheseal, right & $9.00(13)$ & $10.80(7)$ & $7.60(5)$ & $7.10(1)$ \\
\hline & Perientheseal, right & $17.90(26)$ & 13.80 (9) & $19.70(13)$ & $28.60(4)$ \\
\hline & PDUS sum score \pm & $0.59 \pm 0.98$ & $0.66 \pm 1.09$ & $0.58 \pm 0.93$ & $0.36 \pm 0.63$ \\
\hline & SD (range 0-4) & $(0-4)$ & $(0-4)$ & $(0-3)$ & $(0-2)$ \\
\hline \multirow[t]{6}{*}{ Distal patellar tendon } & Intraentheseal, left & $9.00(13)$ & $12.30(8)$ & $6.20(4)$ & $7.10(1)$ \\
\hline & Perientheseal, left & $15.90(23)$ & $23.10(15)$ & $7.60(5)$ & $21.40(3)$ \\
\hline & Intraentheseal, right & $13.10(19)$ & 13.80 (9) & $12.10(8)$ & $14.30(2)$ \\
\hline & Perientheseal, right & $15.90(23)$ & $13.80(9)$ & $16.70(11)$ & $21.40(3)$ \\
\hline & PDUS sum score \pm & $0.59 \pm 1.06$ & $0.67 \pm 1.1$ & $0.49 \pm 1.04$ & $0.64 \pm 1.01$ \\
\hline & SD (range 0-4) & $(0-4)$ & $(0-4)$ & $(0-4)$ & $(0-3)$ \\
\hline \multirow[t]{6}{*}{ Achilles tendon } & Intraentheseal, left & 26.90 (39) & $30.80(20)$ & $21.20(14)$ & $35.70(5)$ \\
\hline & Perientheseal, left & $41.40(60)$ & $43.10(28)$ & $39.40(26)$ & $42.90(6)$ \\
\hline & Intraentheseal, right & $24.90(36)$ & $29.20(19)$ & $21.20(14)$ & $21.40(3)$ \\
\hline & Perientheseal, right & $35.90(52)$ & $35.40(23)$ & $36.40(24)$ & $35.70(5)$ \\
\hline & PDUS sum score \pm & $1.37 \pm 1.32$ & $\mid .4 \mathrm{I} \pm \mathrm{I} .4 \mathrm{I}$ & $1.33 \pm 1.28$ & $1.36 \pm 1.15$ \\
\hline & SD (range 0-4) & $(0-4)$ & $(0-4)$ & $(0-4)$ & $(0-4)$ \\
\hline \multirow[t]{6}{*}{ Plantar fascia } & Intraentheseal, left & $6.90(10)$ & $9.20(6)$ & $1.50(1)$ & $21.40(3)$ \\
\hline & Perientheseal, left & $19.30(28)$ & $30.80(20)$ & $6.10(4)$ & $28.60(4)$ \\
\hline & Intraentheseal, right & 7.60 (II) & $10.80(7)$ & $3.00(2)$ & $14.30(2)$ \\
\hline & Perientheseal, right & $16.60(24)$ & $21.50(14)$ & $9.10(6)$ & $28.60(4)$ \\
\hline & PDUS sum score \pm & $0.54 \pm 0.99$ & $0.75 \pm 1.08$ & $0.23 \pm 0.66$ & $0.93 \pm 1.33$ \\
\hline & SD (range 0-4) & $(0-4)$ & $(0-4)$ & $(0-3)$ & $(0-4)$ \\
\hline
\end{tabular}

Abbreviations: AS, ankylosing spondylitis; PDUS, power Doppler ultrasound; PsA, psoriatic arthritis; PsA with axial, psoriatic arthritis with axial involvement.

\section{Correlation of MASES and PDUS with HAQ, EQ-5D and EQ-VAS}

Poor correlation was observed between MASES and PDUS at baseline, as well as between the changes in MASES and PDUS during the follow-up in relation to patient-reported outcomes (HAQ, EQ-5D, and EQ-VAS); each Pearson's $r<0.5$.

\section{Correlation of the PDUS score with clinical parameters at baseline}

Poor correlation was also observed between PDUS sum score signals and disease severity (BASDAI and DAS28), disease duration and BMI (each Pearson's $r<0.3$ ) at baseline. 


\section{Inter- and intra-reader reliability of the PDUS assessment}

The overall kappa (Cohen's $\kappa$ ) of the inter- and intra-reader reliability for PDUS assessment was 0.7, reflecting good agreement with the PDUS assessment.

\section{Discussion}

Peripheral enthesitis is a hallmark in all subtypes of spondyloarthropathies. Patients with peripheral enthesitis may be asymptomatic, but there is often clinical relevance, including patients with disabling pain. Several studies have revealed that US is more sensitive in the detection of enthesitis than clinical examination. Spadaro et $\mathrm{al}^{5}$ reported that, of 36 patients with AS, $14.8 \%$ had clinically symptomatic enthesitis, whereas $44 \%$ had PD activity at the entheseal sites. Similar results were published in another study ${ }^{6}$ in 92 patients with early PsA; $29 \%$ had tenderness at the entheses, but $40 \%$ exhibited positive PD signals at the entheseal sites. In psoriatic patients without manifestations of arthritis, Gutierrez et $\mathrm{al}^{7}$ reported that one-third of the abnormalities in the entheses as measured using gray scale US were indicative of enthesitis, but PD activity $<1 \%$ was nearly absent in this population.

Except for the Achilles tendon, MASES and the US scoring system applied in our study examined different entheseal sites. Focusing on the Achilles tendon, patients had a higher percentage of clinically symptomatic Achilles tendons than was the proportion of patients with PDUS activity. These results are in contrast with the studies mentioned previously, which indicated a higher sensitivity of US in detecting enthesitis. One possible explanation could be that tenderness at the Achilles tendon, though an ASAS criterion for the classification of axSpA, ${ }^{8}$ is nonspecific. As it is a weight-bearing enthesis, the Achilles tendon is prone to mechanical stress and is often involved in degenerative alterations that can also cause heel pain. Furthermore, tenderness of the Achilles tendon having been one possible inclusion criterion besides pain at other entheses may have caused bias in the patient population. Klauser et $\mathrm{al}^{9}$ systematically investigated all the entheses that were included in the MASES by gray scale and PDUS in 21 rheumatic outpatients with suspected enthesitis. In agreement with our results, $33 \%$ of the patients in the Klauser et al's study ${ }^{9}$ had clinical signs of acute enthesitis at the Achilles tendons, but only $8 \%$ had PD activity. In the Freeston et al's study, ${ }^{10} 57 \%$ of patients with early PsA had clinical evidence of at least one tender enthesis, but only $24 \%$ of the tender entheses showed abnormalities during the US examination. Freeston et al concluded that clinical examination may sometimes overestimate active enthesitis. Falcao et $\mathrm{al}^{11}$ investigated the Achilles tendon of 146 patients with early SpA according to the MASEI score ${ }^{12}$ and reported that of the $26 \%$ of patients with heal pain, $83 \%$ had PD signals compared with $24 \%$ without heel pain. Thus, as per the examination of literature, the issue of US-detected enthesitis is still a matter of debate. ${ }^{13}$ One possible explanation for the inconsistency of data observed may be the various definitions for US enthesitis used in the different studies. In our study, we used the definition proposed by Naredo et al, ${ }^{4}$ in which the presence or absence of intra- and peri-entheseal vascularization is scored. Recently, the OMERACT group ${ }^{3}$ published a consensus statement defining enthesitis in SpA based on US. Further studies should strive to consistently apply the newly proposed definition to hopefully reveal more homogenous results.

With respect to the therapeutic response in our study group, all clinical parameters and scores, as well as the PDUS sum scores, revealed highly significant improvements 3 and 6 months after initiating or intensifying treatment. Our results confirm the data published by Naredo et al, ${ }^{4}$ which reported a significant decrease in peri- and intra-entheseal PD activity in 197 patients with SpA, 6 months after initiating anti-TNF- $\alpha$ therapy. In addition, our data highlight early treatment response, as significant improvement was noted as early as 3 months after beginning therapy. Aydin et $\mathrm{al}^{14}$ described 43 patients with AS with active disease and a decrease in PDUS activity at the Achilles tendon after 2 months of TNF- $\alpha$ therapy; however, the difference was not statistically significant. The relatively small study population and the short follow-up ( 8 weeks) after starting anti-TNF- $\alpha$ therapy may account for the lack of significance of the results.

Because of the chronicity of SpA and the negative effect on the daily lives of patients, patient-reported outcomes are of increasing interest in clinical trials. ${ }^{15}$ The clinical parameters and the health-related quality of life scores also indicated significant improvement during follow-up visits. Surprisingly, we found a poor correlation between the quality of life scores (HAQ and the EQ-5D) with the MASES and the PD score. Thus, our results indicate that pain at the entheseal sites and PD activity may not directly influence the basic abilities of daily living. Therefore, it seems enthesitis is not reflected in these patient related outcomes making it important to analyze enthesitis separately.

Several limitations of our study should be addressed. First, as a multicenter study reflecting daily clinical practice in Germany, the sonographers were not blinded to the diagnoses and the treatment of the patients. Furthermore, the 
rheumatologist who performed the MASES determination also performed the US examination. Knowing the clinical results, a bias in the US evaluation is possible, but nevertheless this is reflecting daily clinical practice. Second, there were different types and qualities of US machines used at the different study centers (ie, medium-range to high-end machines). Thus, the sensitivity of the PD examination may have varied from center-to-center. ${ }^{16}$ Indeed, the detection of low flow at the entheses is dependent on the presets and quality of the US machines at the respective center. This limitation, however, was minimalized by the fact that the follow-up visit of every single patient was performed in the same study center and was conducted by the same sonographer with constant PD settings. According to the study design comparing an established clinical score (MASES) with an established US score, only the Achilles tendon was examined by both methods.

So, a direct comparison between clinical and US findings is not possible. The objective of our study was to evaluate the therapeutic responsiveness of the MASES and the PDUS score in patient with enthesitis in $\mathrm{SpA}$ and the correlation with patients-reported outcome measures. In conclusion, our data confirm that, in our study population clinical assessment by MASES reflects treatment response better than the applied PDUS score, which predominately scored different entheses. However, neither MASES nor PDUS showed a fair correlation with HAQ and EQ-5D.

\section{Acknowledgments}

We thank Imma Fischer, PhD, Tübingen, Germany, and the US and clinical research investigators involved in this study. The study was funded by AbbVie. AbbVie participated in selecting the research investigators, study design, data analysis and interpretation of data, and in the writing, reviewing and approving of the manuscript.

\section{Disclosure}

BW is an AbbVie employee and may hold AbbVie stock or stock options. WH, JS and AN report no conflict of interest in this work.

\section{References}

1. Rudwaleit M, van der Heijde D, Landewe R. The development of Assessment of SpondyloArthritis international Society classification criteria for axial spondyloarthritis (part II): validation and final selection. 2009. Ann Rheum Dis. 2009 Jun;68(6):777-783.

2. Mander M, Simpson JM, McLellan A, Walker D, Goodacre JA, Dick WC. Studies with an enthesis index as a method of clinical assessment in ankylosing spondylitis. Ann Rheum Dis. 1987;46(3):197-202.

3. Terslev L, Naredo E, Iagnocco A, et al. Defining enthesitis in spondyloarthritis by ultrasound: results of a Delphi process and of a reliability reading exercise. Arthritis Care Res (Hoboken). 2014;66(5):741-748.

4. Naredo E, Batlle-Gualda E, García-Vivar ML, et al. Power Doppler ultrasonography assessment of entheses in spondyloarthropathies: response to therapy of entheseal abnormalities. J Rheumatol. 2010;37(10):2110-2117.

5. Spadaro A, Iagnocco A, Perrotta FM, Modesti M, Scarno A, Valesini G. Clinical and ultrasonography assessment of peripheral enthesitis in ankylosing spondylitis. Rheumatology (Oxford). 2011;50(11):2080-2086.

6. Bandinelli F, Prignano F, Bonciani D, et al. Ultrasound detects occult entheseal involvement in early psoriatic arthritis independently of clinical features and psoriasis severity. Clin Exp Rheumatol. 2013;31(2):219-224.

7. Gutierrez M, Filippucci E, De Angelis R, et al. Subclinical entheseal involvement in patients with psoriasis: an ultrasound study. Semin Arthritis Rheum. 2011;40(5):407-412.

8. Sieper J, Rudwaleit M, Baraliakos X, et al. The Assessment of Spondylo Arthritis international Society (ASAS) handbook: a guide to assess spondyloarthritis. Ann Rheum Dis. 2009;68(Suppl 2):ii1-ii44.

9. Klauser AS, Wipfler E, Dejaco C, Moriggl B, Duftner C, Schirmer M. Diagnostic values of history and clinical examination to predict ultrasound signs of chronic and acute enthesitis. Clin Exp Rheumatol. 2018;26:548-553.

10. Freeston JE, Coates LC, Helliwell PS, et al. Is there subclinical enthesitis in early psoriatic arthritis? A clinical comparison with power Doppler ultrasound. Arthritis Care Res (Hoboken). 2012;64(10):1617-1621.

11. Falcao S, Castillo-Gallego C, Peiteado D, Branco J, Martín Mola E, de Miguel E. Can we use enthesis ultrasound as an outcome measure of disease activity in spondyloarthritis? A study at the Achilles level. Rheumatology (Oxford). 2015;54(9):1557-1562.

12. de Miguel E, Cobo T, Muñoz-Fernández S, et al. Validity of enthesis ultrasound assessment in spondyloarthropathy. Ann Rheum Dis. 2009;68(2):169-174.

13. Mandl P, Niedermayer DS, Balint PV. Ultrasound for enthesitis: handle with care! Ann Rheum Dis. 2012;71(4):477-479.

14. Aydin SZ, Karadag O, Filippucci E, et al. Monitoring Achilles enthesitis in ankylosing spondylitis during TNF-alpha antagonist therapy: an ultrasound study. Rheumatology (Oxford). 2010;49(3):578-582.

15. Wheaton L, Pope J. The minimally important difference for patient-reported outcomes in spondyloarthropathies including pain, fatigue, sleep, and Health Assessment Questionnaire. J Rheumatol. 2010;37(4):816-822.

16. Torp-Pedersen S, Christensen R, Szkudlarek M, et al. Power and color Doppler ultrasound settings for inflammatory flow: impact on scoring of disease activity in patients with rheumatoid arthritis. Arthritis Rheumatol. 2015;67(2):386-395.
Open Access Rheumatology: Research and Reviews

\section{Publish your work in this journal}

Open Access Rheumatology: Research and Reviews is an international, peerreviewed, open access journal publishing original research, reports, editorials reviews and commentaries on all aspects of clinical and experimental rheumatology in the clinic and laboratory including the following topics: Pathology, pathophysiology of rheumatological diseases; Investigation, treatment and

\section{Dovepress}

management of rheumatological diseases; Clinical trials and novel pharmacologi$\mathrm{cal}$ approaches for the treatment of rheumatological disorders. The manuscript management system is completely online and includes a very quick and fair peer-review system, which is all easy to use. Visit http://www.dovepress.com/ testimonials.php to read real quotes from published authors. 